have been carried out. A first analysis has been conducted using Alceste software in order to identify semantic universes. The second analysis was a thematic one. Observations have enabled to relate discourses on the one hand and actual prevention work activities on the other.

Results Effects induced by measurable outcomes cause several types of reactions, among which: the questioning of professional identities, the emergence of local forms of negotiation, internal tensions between the members of health at work services.

Conclusion When intervening in work settings, health prevention professionals used to be very critical of the use of measurable outcomes. The ultimate paradox is that it is now their turn to submit to similar organisational and managerial constraints.

\section{EVALUATION OF AN ONLINE INTERVENTION TOOL TO PREVENT EXPOSURE TO WORKPLACE BULLYING}

\footnotetext{
1,2,3 Whitney Van den Brande*, 2,4Elfi Baillien, ${ }^{1,3}$ Tinne Vander Elst, ${ }^{3,5}$ Hans De Witte, 1,6 Lode Godderis. 'Knowledge, Information and Research Centre (KIR, IDEWE Group), Leuven, Belgium; ${ }^{2}$ Research Department Work and Organisation Studies (KU Leuven), Brussels, Belgium; ${ }^{3}$ Research Group Work, Organisational and Personnel Psychology (KU Leuven), Leuven,Belgium; ${ }^{4}$ Department of Pyschosocial Sience, University of Bergen, Norway; ${ }^{5}$ Optentia Research Focus Area (North-West University), Vanderbijlpark Campus, South Africa; ${ }^{6}$ Centre for Environment and Health (KU Leuven), Leuven, Belgium
}

\subsection{6/oemed-2018-ICOHabstracts. 1608}

Introduction Researchers have underlined the need to address risk factors for workplace bullying by conducting intervention studies. Given the important role of coping strategies, we developed an online intervention tool to teach employees using efficient coping strategies. In this study, we investigated the impact of this online intervention. We hypothesised that the intervention:

1. decreased emotion-focused coping strategies,

2. stimulated self-efficacy, and

3. reduced exposure to bullying.

Methods Longitudinal data were collected in a cross-over study in which participants were assigned to two experimental groups (group 1 and 2) or a control group (group 3). The participants were contacted three times over a period of eight months (time lag of four months between subsequent measurement points) to complete either an online questionnaire or the online intervention. In group 1, participants participated in the intervention during the first four months, including a premeasurement questionnaire and post-measurements after four and eight months. The second group participated in the intervention after four months, including pre-measurements and post-measurements after eight months. The third group did not receive the intervention and only completed the online questionnaire.

Result MANCOVA analyses and non-parametric tests were performed. Results showed that the mean level of exposure to bullying after completing the intervention was lower in both experimental groups compared to the control group. This may indicate that the intervention had an impact on exposure to bullying. However, within-group analysis revealed no significant decrease in workplace bullying over time within group 2 . Further, the means of emotion-focused coping strategies (i.e., mental and behavioural disengagement) were lower in group 2 in comparison with the control group. This may indicate that the intervention discouraged using emotion-focused coping strategies. No significant differences were found for selfefficacy.

Discussion Future research needs to define contextual factors that are necessary to successfully implement this online intervention.

\section{EVALUATION OF FACILITATORS TRAINING IN IMPROVING THE WORKPLACE ENVIRONMENT USING A PARTICIPATORY APPROACH FOR PRIMARY PREVENTION IN MENTAL HEALTH}

${ }^{1}$ E Yoshikawa*,${ }^{2} \mathrm{~T}$ Yoshikawa, ${ }^{3} \mathrm{Y}$ Takeuchi, ${ }^{3} \mathrm{Y}$ Sano, ${ }^{1} \mathrm{~A}$ Yuasa, ${ }^{3} \mathrm{~K}$ Kogi. ${ }^{1}$ Japanese Red Cross College of Nursing, Tokyo, Japan; ${ }^{2}$ National Institute of Occupational Safety and Health, Kawasaki, Japan; ${ }^{3}$ The Ohara Memorial Institute for Science of Labour, Tokyo, Japan

\subsection{6/oemed-2018-ICOHabstracts.1609}

Introduction The efficacy of a training program conducted for learning actions taken by facilitators engaged in promoting workplace environment improvements using a participatory approach for primary prevention in mental health was studied. The study was aimed at clarifying the effects of the training program on learning their role in facilitating workplace-level improvement actions.

Methods We conducted a three-and-a-half-hour facilitators training program in Tokyo. The participants included 21 occupational health practitioners. After the training, we distributed a questionnaire (response rate: 95.2\%) and studied the effects of the training program. The average years of experience of the respondents was $11.5 \pm 7.6$ years, and the respondents included six persons who had experience in activities to improve their workplace environment. The relation between the level of understanding of the training contents and the respondents' level of confidence about the learning results was analysed by using a chi-squared test.

Results All the respondents answered that they could understand the significance of improving the workplace environment using a participatory approach as well as the role of a facilitator. They evaluated the content of the training as generally high and agreed with the need for taking action-oriented steps applying participatory methods. Concerning the level of confidence about supporting improvement activities, eight respondents (42\%) replied 'very confident' or 'somewhat confident,' and 11 (58\%) 'somewhat unconfident' or 'not confident at all.' The chi-square test did not reveal any statistically significant difference between groups on either item.

Conclusion The facilitators training in promoting the participants' understanding concerning the significance of improving the workplace environment was confirmed effective by using a participatory approach. It has been suggested that, in order to enable the participants to effectively practice at their workplace what they learned from the training, it is important to provide a thorough follow-up after the training. 2 